\title{
A phase I/II study of weekly nab-paclitaxel plus cisplatin in chemotherapy-naïve patients with advanced non-small-cell lung cancer
}

Yoshihiro Hattori ${ }^{1}$, Yuko Kono ${ }^{1}$, Shoichi Itoh' ${ }^{1}$, Takako Inoue ${ }^{2}$, Yoshiko Urata', Yoshitaka Kawa ${ }^{1}$, Rie Tohnai ${ }^{1}$, Toru Kumagai ${ }^{2}$, Kazumi Nishino ${ }^{2}$, Ryuji Uozumi ${ }^{3}$, Satoshi Morita ${ }^{3}$, Shunichi Negoro ${ }^{4}$, Fumio Imamura ${ }^{2}$ and Miyako Satouchi ${ }^{1 *}$ (D)

\begin{abstract}
Background: The aim of this study was to evaluate the efficacy and safety of nab-paclitaxel plus cisplatin in chemotherapy-naïve patients with advanced non-small-cell lung cancer (NSCLC).

Methods: Chemotherapy-naïve patients with advanced NSCLC were eligible. In the phase I dose-escalation cohort ( $3+3$ design), patients received nab-paclitaxel ( 80 or $100 \mathrm{mg} / \mathrm{m}^{2}$ given intravenously on days 1,8 and 15) plus cisplatin ( 60 or $75 \mathrm{mg} / \mathrm{m}^{2}$ given intravenously on day 1 ) every 4 weeks. The maximum tolerated dose was not reached. Nab-paclitaxel $\left(100 \mathrm{mg} / \mathrm{m}^{2}\right.$ given intravenously on days 1,8 and 15$)$ plus cisplatin $\left(75 \mathrm{mg} / \mathrm{m}^{2}\right.$ given intravenously on day 1) every 4 weeks was selected for the phase II cohort. The primary endpoint was the objective response rate (ORR).

Results: Twenty-three patients (phase I, $n=6$; phase $\|, n=17$ ) were enrolled, and 22 patients were eligible. The median age was 67.5 years (range $37-75)$, 90.9\% were males, $45.5 \%$ had adenocarcinoma and $81.8 \%$ had stage IV disease. The ORR was $59.1 \%$ (90\% confidence interval (Cl); 41.8-74.4), and the disease control rate was $86.4 \%$ (95\% $\mathrm{Cl}$; 66.7-95.3). The median progression-free survival was 5.1 months (95\% $\mathrm{Cl} ; 4.0-6.7)$, and the median overall survival was 24.2 months ( $95 \% \mathrm{Cl} ; 8.4$ months to not estimable). The common grade $\geq 3$ adverse events were neutropenia (31.8\%), leukopenia (27.3\%), lung infection (18.2\%) and hyponatremia (18.2\%). There was one instance of grade 2 interstitial pneumonia and no treatment-related death.
\end{abstract}

Conclusions: Nab-paclitaxel plus cisplatin was well tolerated and associated with encouraging response outcomes in chemotherapy-naïve patients with advanced NSCLC. Further investigation is warranted.

Trial registration: UMIN Clinical Trials Registry: UMIN000011776; Date of registration: 17 September 2013; Date of enrolment of the first participant to the trial: 23 January 2014.

Keywords: Nab-paclitaxel, Cisplatin, Non-small-cell lung cancer, Chemotherapy-naïve patients

\footnotetext{
* Correspondence: satouchi@hp.pref.hyogo.jp

'Department of Thoracic Oncology, Hyogo Cancer Center, 13-70 Kitaoji-cho,

Akashi-shi, Hyogo 673-8558, Japan

Full list of author information is available at the end of the article
}

(C) The Author(s). 2020 Open Access This article is distributed under the terms of the Creative Commons Attribution 4.0 International License (http://creativecommons.org/licenses/by/4.0/), which permits unrestricted use, distribution, and reproduction in any medium, provided you give appropriate credit to the original author(s) and the source, provide a link to the Creative Commons license, and indicate if changes were made. The Creative Commons Public Domain Dedication waiver (http://creativecommons.org/publicdomain/zero/1.0/) applies to the data made available in this article, unless otherwise stated. 


\section{Background}

It is difficult to cure advanced non-small-cell lung cancer (NSCLC); however, especially in the last few years, the firstline treatment strategies in NSCLC have undergone significant changes. Prior to first-line treatment, mutations in driver oncogenes such as EGFR and $A L K$ were analyzed, and if they were positive, a molecular targeting agent was selected. For patients in which the driver oncogene is negative or unknown, immune checkpoint inhibitors (ICIs) alone or in combination with cytotoxic drugs, depending on the programmed cell death-ligand 1 (PD-L1) status in the tumor and the tissue type, have been introduced as first-line treatments. However, treatment with cytotoxic drugs remains one of the standard therapies because sometimes it is difficult to use ICIs as the first-line treatment (e.g., in patients with interstitial pneumonia or autoimmune disease).

Nab-paclitaxel is a $130 \mathrm{~nm}$ uniform nanoparticle paclitaxel formulation comprised of paclitaxel and human serum albumin. It does not require Cremophor or anhydrous ethanol solvents to formulate, meaning that steroids or antihistamines do not necessarily have to be taken as pretreatments to suppress anaphylactic symptoms. It also allows for quicker administration than solvent-based paclitaxel (sb-paclitaxel). It may also improve the delayed sensory impairment caused by Cremophor [1-3]. The different properties of nabpaclitaxel compared to sb-paclitaxel also point to its better distribution within tumors than sb-paclitaxel (in vitro) [4]. Meanwhile, in terms of toxicity, the incidence of peripheral neuropathy, which is a concern with sb-paclitaxel, was significantly lower with weekly nab-paclitaxel plus carboplatin than with sb-paclitaxel, and it resulted in a shorter time to recovery from grade $\geq 3$ neuropathy to grade 1 .

It has been reported that sb-paclitaxel plus cisplatin extends median overall survival (mOS) more than etoposide plus cisplatin (9.9 months vs. 7.6 months; $p=0.48$ ); as such, it has come to be considered a SOC [5].

Meanwhile, carboplatin, a derivative of cisplatin, does not require large-volume transfusion to prevent renal dysfunction and came into widespread clinical application in the 2000s. As reported by Rosell et al. in a phase III clinical study comparing sb-paclitaxel plus cisplatin to sb-paclitaxel plus carboplatin [6], sb-paclitaxel plus cisplatin was shown to be noninferior in terms of the primary endpoint of response rate $(p=0.45)$, but the mOS was 9.8 months in the sb-paclitaxel plus cisplatin arm (95\% confidence interval (CI); 8.2-11 months) as opposed to 8.2 months in the sb-paclitaxel plus carboplatin arm (95\% CI; 7.4-9.6 months), indicating that the sb-paclitaxel plus carboplatin arm was significantly inferior (hazard ratio (HR) 1.22; 90\% CI 1.06-1.40; $p=0.019$ ). The toxicity profile, however, was generally favorable in the sb-paclitaxel plus carboplatin arm, and it is easy to administer; as such, the platinum agent that is usually combined with sb-paclitaxel is carboplatin (more so than cisplatin). Moreover, a Japanese phase II study on sbpaclitaxel plus cisplatin also showed promising results; the response rate was $31 \%$ (95\% CI; $16-50 \%)$, and the mOS was 14.8 months [7]. There have been, however, reports of grade $\geq 3$ neuropathy at incidences ranging between 23 and 40\% [5], highlighting the strong neurotoxicity issues. As such, the combination has not been used in the real-world clinical setting.

There have been multiple meta-analysis reports of comparisons between cisplatin and carboplatin to date, and they have reported no significant difference in survival [8-10]. The meta-analysis conducted by Ardizzoni et al. featured a cisplatin combination displaying a superior response rate to carboplatin (HR 1.37; 95\% CI $1.16-1.61 ; p<0.001)$. Moreover, when combined with a 3rd generation anticancer agent, cisplatin allowed for significantly more favorable survival than carboplatin (HR 1.11; 95\% CI 1.01-1.21) [10]. Weekly nab-paclitaxel plus carboplatin actually displayed superiority over sbpaclitaxel plus carboplatin in CA031 [11], a multicenter international phase III controlled trial on lung cancer (the response rates were 33 and 25\%, respectively; $p=$ 0.005 ), in terms of all-grade sensory neuropathy (47 and $62 \%$, respectively) as well as grade $\geq 3$ adverse events (3 and $11 \%$, respectively). The use of FACT-taxane also showed significantly more favorable results in the weekly nab-paclitaxel plus carboplatin arm than in the control arm. Accordingly, the neurotoxicity issue seen with sbpaclitaxel plus cisplatin conceivably could be reduced by switching the sb-paclitaxel to weekly nab-paclitaxel. Weekly nab-paclitaxel plus cisplatin may improve the toxicity profile compared with sb-paclitaxel plus cisplatin and may be a more effective therapy. As such, we planned a phase I/II study of the efficacy and safety of weekly nab-paclitaxel plus cisplatin in advanced NSCLC.

\section{Methods}

\section{Patient eligibility}

Eligible patients had histologically or cytologically confirmed NSCLC, stage IIIB or IV disease (diagnosed according to the seventh edition of the Union for International Cancer Control staging system) or suffered a recurrence after surgery, had no driver oncogenes (e.g., EGFR, $A L K$, $R O S 1$, or $R E T$ ) and were aged $\geq 20$ years. Patients were also required to have measurable lesions as defined by $\mathrm{Re}$ sponse Evaluation Criteria in Solid Tumors (RECIST) version 1.1; an Eastern Cooperative Oncology Group (ECOG) PS of 0 or 1 ; a life expectancy $\geq 3$ months; and adequate bone marrow, hepatic, and renal function. Patients with interstitial pneumonia or pulmonary fibrosis recognized on computed tomography (CT) scans, uncontrolled pleural effusions or symptomatic brain metastases were deemed to be ineligible. 
The protocol was approved by institutional ethical review boards in each of the participating institutes, and all patients provided written informed consent before enrollment. The study was conducted in accordance with the ethical principles in the Declaration of Helsinki. The study has been registered under the University Medical Hospital Information Network (UMIN) Clinical Trials Registry: identifier UMIN 000011776.

\section{Study design and treatment}

The study was designed as a prospective, multicenter, single-arm phase I/II study of first-line combination therapy with nab-paclitaxel and cisplatin. The recommended dose (RD) was determined in phase I, and the efficacy and safety were assessed in phase II. Study design and treatment are presented in Fig. 1. The primary endpoint was treatment efficacy measured as the objective response rate (ORR) in patients who had received at least one cycle of the initial combination therapy. Disease control rate (DCR), overall survival (OS), progression-free survival (PFS), and adverse events (AEs) were also evaluated as secondary endpoints.

Patients received cisplatin at a dose of $60-75 \mathrm{mg} / \mathrm{m}^{2}$ given intravenously on day 1 and nab-paclitaxel at a dose of $80-100 \mathrm{mg} / \mathrm{m}^{2}$ given intravenously on days 1,8 , and 15 . The combination therapy was repeated every 28 days for up to six cycles unless there was evidence of PD or intolerance of the study treatment. Subsequent cycles of treatment were withheld until the following criteria were satisfied: leucocyte count $\geq 3000 / \mu \mathrm{L}$; neutrophil count $\geq 1500 / \mu \mathrm{L}$; platelet count $\geq 100,000 / \mu \mathrm{L}$; PS $0-1$; aspartate aminotransferase $\leq 3.0 \times$ upper limit of normal (ULN); alanine aminotransferase $\leq 3.0 \times$ ULN; serum total bilirubin $\leq 1.5 \times \mathrm{ULN}$; serum creatinine $\leq 1.2 \mathrm{mg} / \mathrm{dL}$; grade $\leq 2$ nonhematological toxicities; grade $\leq 2$ peripheral neuropathy; and no infection with fever of at least $38^{\circ} \mathrm{C}$.

\section{Dose-escalation scheme}

In phase I, treatment was started at level 1 (cisplatin 75 $\mathrm{mg} / \mathrm{m}^{2}$, nab-paclitaxel $80 \mathrm{mg} / \mathrm{m}^{2} \mathrm{q} 4 \mathrm{w}$ ). Three patients were initially treated, and if dose-limiting toxicity (DLT) was not observed, we decided to move to level 2 (cisplatin $75 \mathrm{mg} / \mathrm{m}^{2}$, nab-paclitaxel $100 \mathrm{mg} / \mathrm{m}^{2} \mathrm{q} 4 \mathrm{w}$ ). If DLT was observed in $1 / 3$ patients at level 1,3 patients were added. If DLT was observed in $2 / 6$ patients or less, we moved to level 2. If DLT was observed in $3 / 6$ patients or more, we considered level 1 as the MTD, and we decided to examine level 0 (cisplatin $60 \mathrm{mg} / \mathrm{m}^{2}$, nabpaclitaxel $80 \mathrm{mg} / \mathrm{m}^{2} \mathrm{q} 4 \mathrm{w}$ ). If DLT was observed in $0 / 3$ patients at level 2, we considered level 2 as the RD. If DLT was observed in 1/3 patients at level 1,3 patients were added. If DLT was observed in $2 / 6$ patients or less, we considered level 2 as the RD. If DLT was observed in $3 / 6$ patients or more, we considered level 2 as the MTD and level 1 as the RD.

DLT was evaluated by the National Cancer Institute Common Terminology Criteria (NCI-CTC) for Adverse Events version 4.0 and was defined as any of the following during the first cycle of the protocol treatment at each level: leukopenia of grade 4 that lasted more than 4 days, febrile neutropenia, thrombocytopenia of grade 4 or requirement of platelet transfusion, nonhematological

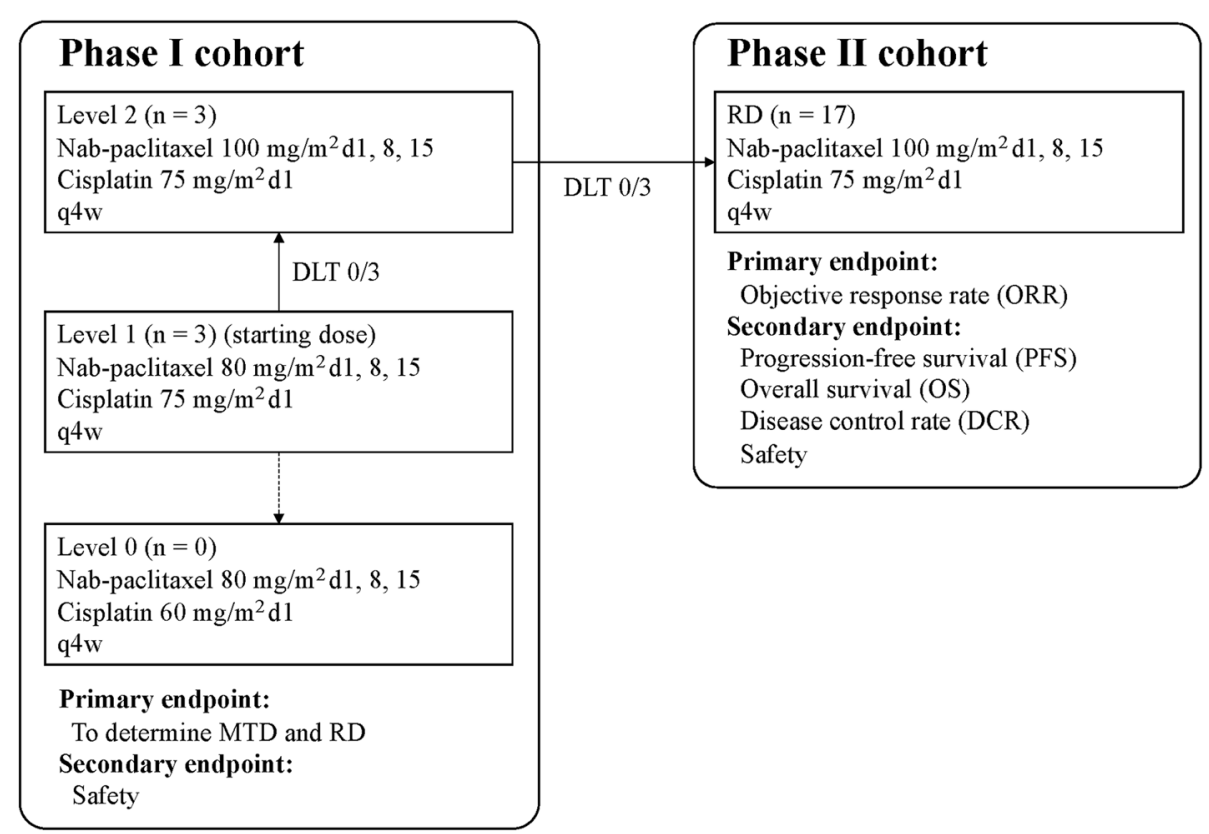

Fig. 1 Study design and treatment 
toxicity of grade 3 or higher (without nausea, vomiting, anorexia, constipation, and electrolyte abnormalities), and no administration of nab-paclitaxel on days 8 and 15.

\section{Baseline and treatment assessments}

The baseline evaluations included medical history, physical examination, electrocardiogram, ECOG performance status, and laboratory analyses. CT scans of the chest and the upper abdomen, magnetic resonance imaging (MRI) studies or CT scans of the brain, and bone scintigraphy or positron emission tomography (PET)-CT studies were performed for tumor assessment within 28 days of initiation of the study treatment. Tumor measurements were assessed with chest X-ray, CT scans, MRI studies, or bone scintigraphy or PET-CT studies. CT scans were repeated every 2 cycles until PD, MRI studies or CT scans of the brain were repeated every 3 months or upon the appearance of any neurologic symptoms, and bone scintigraphy or PET-CT studies were performed every 6 months or upon the appearance of any bone-related symptoms. Objective tumor responses were based on RECIST version 1.1. The ORR was confirmed via extramural review. Toxicity evaluations were based on NCI-CTC version 4.0.

\section{Statistical analysis}

Analyses of efficacy and safety were based on a December 2017 database lock. On the basis of previous studies [7], we assumed that an ORR of $40 \%$ in eligible patients would indicate potential usefulness, while an ORR of $20 \%$ would be the lower limit of interest. The number of patients needed to provide $80 \%$ power with a one-sided significance level of $5 \%$ was calculated to be 32 . Taking ineligible patients into account, we intended to enroll 35 patients. Efficacy and safety analyses were planned for patients who received at least one dose of the treatment. Efficacy analysis included patients enrolled in phase I and phase II. The ORR was defined as the proportion of patients achieving the best response of complete response (CR) or partial response (PR) and summarized by a binomial response rate. The two-sided $90 \% \mathrm{CI}$, which corresponded to a one-sided significance level of 0.10 , was presented using the Wilson method [12] with respect to the efficacy primary endpoint of ORR. The DCR was defined as the proportion of patients achieving CR/ PR or stable disease (SD), summarized by a binomial response rate, and assessed with the corresponding 95\% CIs. PFS and OS were analyzed using the Kaplan-Meier method to estimate the median values with the corresponding 95\% CIs using the Brookmeyer-Crowley method [13]. All analyses were performed using SAS version 9.4 (SAS Institute, Cary, NC, USA).

\section{Results}

\section{Dose escalation}

First, 3 patients were treated with level 1 , and DLT was not observed. Next, we moved to level 2, and 3 patients were treated, but DLT was not observed. Therefore, level 2 was decided as the RD.

\section{Patient characteristics and treatment}

Twenty-three patients (phase I cohort, $n=6$; phase II cohort, $n=17$ ) were enrolled from October 2013 to September 2017. The study was terminated before the targeted initial sample size was met because of poor accrual. One patient was excluded from the analysis because of disease progression before the protocol treatment was started. After excluding 1 ineligible patient, 22 patients were ultimately evaluated. The baseline characteristics are shown in Table 1 . The median age was 67.5 years (range, $37-75$ years), 10 patients (45.5\%) had adenocarcinoma histology, 18 patients $(81.8 \%)$ had stage IV disease, and all patients $(100 \%)$ were smokers. The median number of treatment cycles was 4 (range, 1-6).

\section{Efficacy}

Tumor responses are shown in Table 2. The ORR was $59.1 \%$ (90\% CI; $41.8-74.4 \%$ ), and the DCR was $86.4 \%$ (95\% CI; 66.7-95.3\%). The maximum changes in tumor measurements are presented in Fig. 2. The median PFS was 5.1 months (95\% CI; 4.0-6.7 months) (Fig. 3a), and the median OS was 24.2 months (95\% CI; 8.4 months to not estimable (NE)) (Fig. 3b). The OS was 19.8 months (95\% CI; 6.7 months to NE) in squamous cell lung

Table 1 Patient characteristics

\begin{tabular}{lll}
\hline Characteristics & & $n=22$ \\
\hline Age & Median (range) & $67.5(37-75)$ \\
Sex, (\%) & Male & $20(90.9)$ \\
ECOG PS, $n$ (\%) & Female & $2(9.1)$ \\
& 0 & $4(18.2)$ \\
Smoking history, $n$ (\%) & Never & $18(81.8)$ \\
& Ever/current & $0(0.0)$ \\
Histology, $n$ (\%) & Adenocarcinoma & $22(100)$ \\
& Squamous cell carcinoma & $10(45.5)$ \\
& NSCLC, NOS & $5(31.8)$ \\
Stage (UICC7), $n$ (\%) & IIIB & $4(18.2)$ \\
& IV & $18(81.8)$ \\
& Postoperative recurrence & $0(0.0)$ \\
EGFR mutation, $n$ (\%) & Negative & $21(95.5)$ \\
& Unknown & $1(4.5)$ \\
ALK transfusion, $n$ (\%) & Negative & $20(90.9)$ \\
& Unknown & $2(9.1)$ \\
\hline
\end{tabular}


Table 2 Tumor response in evaluable patients according to RECIST

\begin{tabular}{ll}
\hline & $n=22$ \\
\hline Objective response & $0(0.0)$ \\
Complete response, $n(\%)$ & $13(59.1)$ \\
Partial response, $n(\%)$ & $6(27.3)$ \\
Stable disease, $n(\%)$ & $3(13.6)$ \\
Progressive disease, $n(\%)$ & $0(0.0)$ \\
Not evaluable, $n$ (\%) & $13(59.1)$ \\
Objective response rate (\%) & $41.8-74.4$ \\
$90 \% \mathrm{Cl}, \%$ & $19(86.4)$ \\
Disease control rate (\%) & $66.7-95.3$ \\
$95 \% \mathrm{Cl}, \%$ &
\end{tabular}

cancer (SqCC) and 24.2 months (95\% CI; 6.3 months to $\mathrm{NE}$ ) in non-SqCC (Fig. 3c).

\section{Toxicity}

Twenty-two patients who received the study treatment were deemed eligible for safety analysis. Hematologic AEs and nonhematologic AEs that occurred in $\geq 10 \%$ of patients are shown in Table 3 . The grade $3 / 4$ hematologic AEs were neutropenia (31.8\%), leukopenia (27.3\%), anemia, and febrile neutropenia ( $4.5 \%$ each). The grade $3 / 4$ nonhematologic AEs were hyponatremia and lung infection (18.2\% each) and anorexia, fatigue, hyperkalemia, increased serum amylase, increased lipase, seizure, glaucoma, retinopathy, and hypoxia ( $4.5 \%$ each). There was one instance of grade 2 interstitial pneumonia, and there was no treatment-related death.

\section{Discussion}

We conducted a phase I/II multicenter joint clinical study on weekly nab-paclitaxel plus cisplatin in treatment-naïve advanced NSCLC patients. The issue, however, was the rapid development of ICIs during the study, including robust development of treatment with combinations of ICIs and chemotherapy, which resulted in slow accrual and eventual completion of the study with a smaller sample than originally planned.

The primary endpoint, ORR, was $59.1 \%$, which was higher than that observed in the CA031 study (33\%) and its Japanese subset (35\%). While weekly nab-paclitaxel plus carboplatin has displayed a more favorable response rate in $\mathrm{SqCC}$ ( $41 \%$ in the CA031 study and $50 \%$ in its Japanese subset), the proportion of $\mathrm{SqCC}$ in this study (31.8\%) was not so high as compared to the CA031 study (44\%) and its Japanese subset (14\%).

The median PFS (mPFS) was 5.1 months, as opposed to 6.3 and 6.9 months in CA031 and the Japanese subset, respectively, indicating an inferior mPFS. The study enrolled a small number of patients, and the confidence interval was relatively large, making it difficult to determine the quality of these outcomes. It is conceivable that the fact that our study established a maximum of 6 cycles, whereas CA031 did not have a set maximum in place, could have had an influence on the outcomes. Meanwhile, considering that the OS in our study was relatively favorable, weekly nab-paclitaxel plus cisplatin most likely had a minimal impact on subsequent treatments.

Pemetrexed maintenance is one of the standard regimens for first-line treatment of nonsquamous NSCLC. The OS of nonsquamous NSCLC in this study seems to be comparable to the that found in the PARAMOUNT

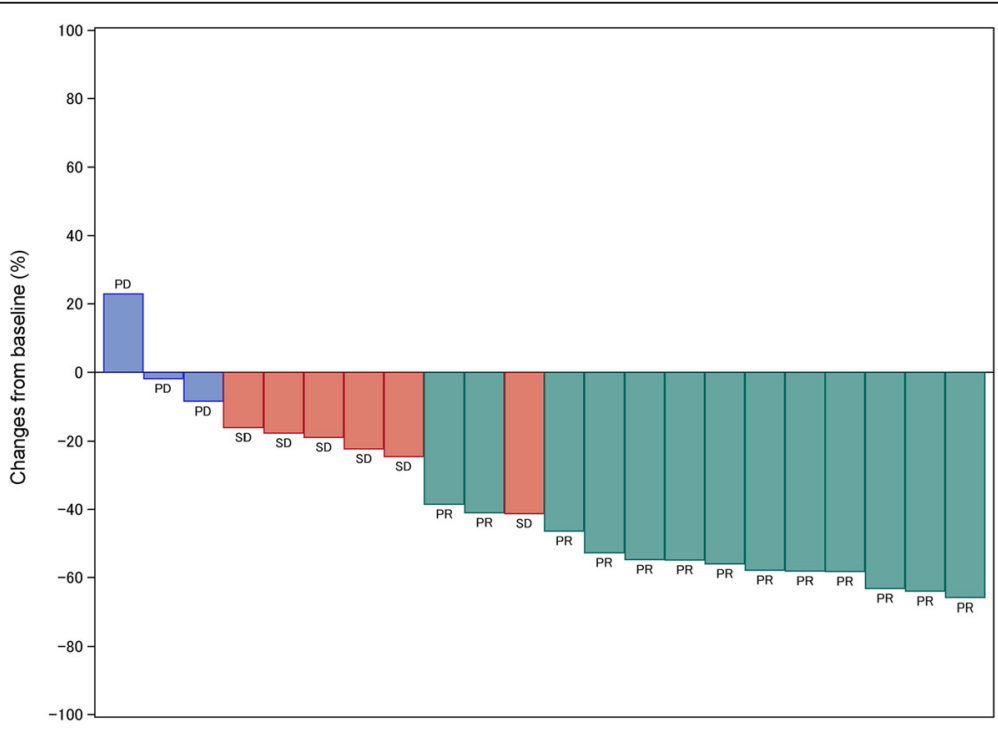

Fig. 2 Waterfall plot of best change from baseline 


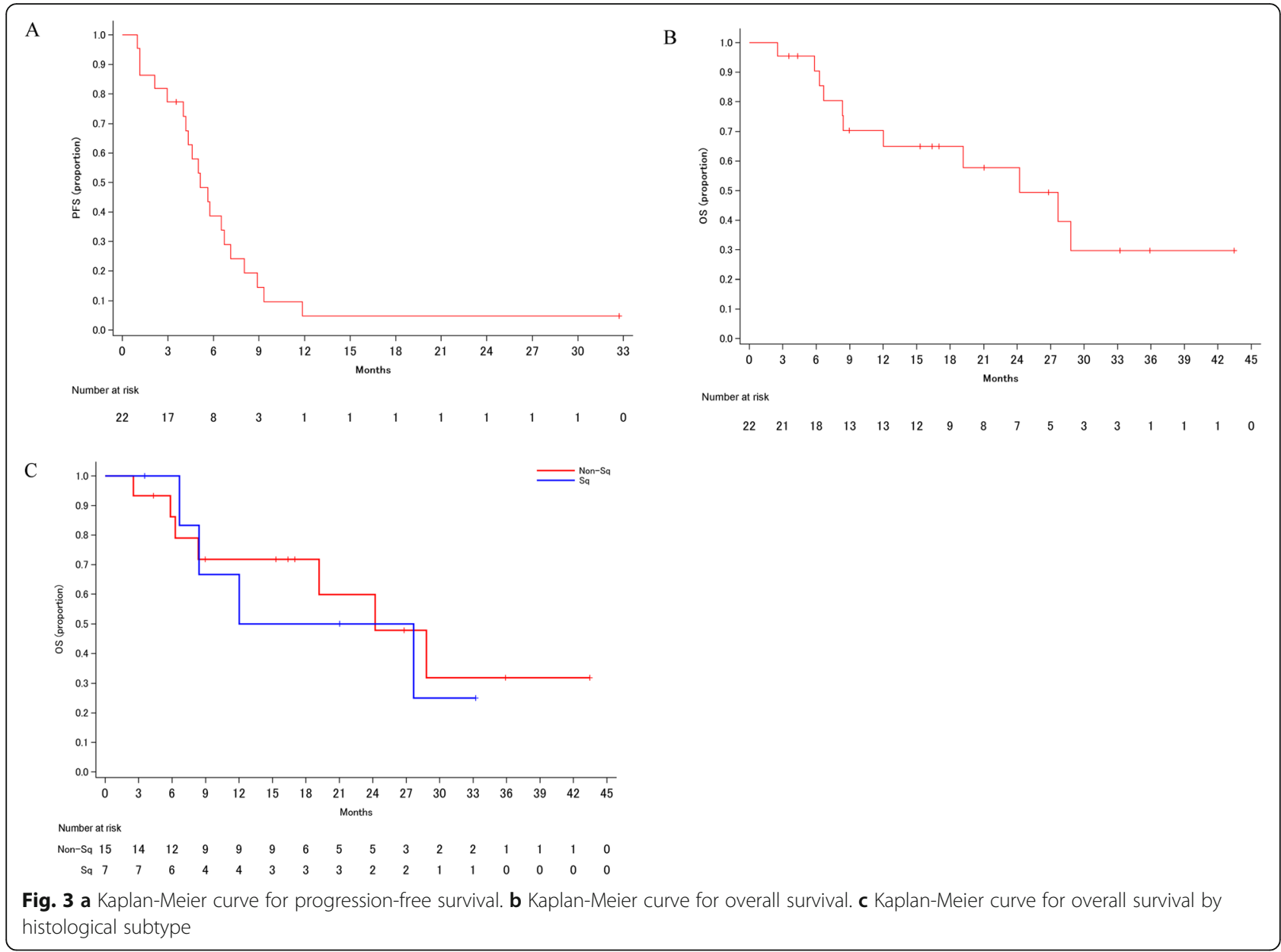

trial [14]. However, it is a limitation that the sample size of our study was small.

No particularly new toxicities were observed above and beyond those seen in other studies to date. Analysis of the Japanese subset in CA031 showed a delay in the initiation of a subsequent course of treatment in $64.3 \%$ of the patients, and the median delay was 8 days. Based on these findings, we administered nab-paclitaxel on days 1,8 , and 15 , skipping 1 week, in a 4 -week cycle. We feel that this maintained the dose intensity that was seen in CA031. Due to the altered schedule, the incidence of all-grade hematological toxicity was virtually the same as that in previous reports. The incidence of grade $3 / 4$ neutropenia was slightly higher (31.8\%) than that in CA031 but lower than that in the Japanese subset of CA031 (69\% of $\geq$ Grade 3). In general, myelosuppression in Japanese patients tends to be strong, but it is considered acceptable. There was no hematological toxicity, as in CA031, which frequently requires dose delays and reductions, which facilitated handling. In regard to nonhematological toxicity, there was no particular increase in sensory peripheral neuropathy compared with CA031. While hyponatremia was observed in a relatively large percent of patients, it was adequately manageable. Additionally, while grade $\geq 3$ lung infections were observed in 4 patients $(18.2 \%)$, they all improved. Although grade 2 ILD was observed in 1 patient, there were no treatmentrelated deaths; safety was within the permissible range.

In recent years, combination therapies consisting of platinum-based combination therapy and ICIs have been developed. In fact, the outcomes from the KEYNOTE407 trial showed that pembrolizumab added to weekly nab-paclitaxel plus carboplatin prolonged survival [15] and improved health-related quality of life (HRQoL) [16], and it is being introduced into the clinical setting. Recently, the results of the IMpower130 trial also demonstrated the efficacy of the nab-paclitaxel regimen in nonsquamous NSCLC, which has also been introduced into the clinical setting [17]. Moreover, the efficacy and safety of nab-paclitaxel plus carboplatin have been reported in patients with NSCLC with interstitial lung disease [18]. Given that the combination of nab-paclitaxel and platinum salts has been reported to be effective, the results of our study are promising for the future treatment of NSCLC. With reports stating that the combination of nab-paclitaxel and platinum is effective, the 
Table 3 Treatment-related adverse events $(n=22)$

\begin{tabular}{|c|c|c|}
\hline n (\%) & All grade & Grade $3 / 4$ \\
\hline \multicolumn{3}{|l|}{ Hematologic adverse events } \\
\hline Leukopenia & $19(86.4)$ & $6(27.3)$ \\
\hline Neutropenia & $20(90.9)$ & $7(31.8)$ \\
\hline Anemia & $22(100.0)$ & $1(4.5)$ \\
\hline Thrombocytopenia & $5(22.7)$ & $0(0)$ \\
\hline Febrile neutropenia & $1(4.5)$ & $1(4.5)$ \\
\hline \multicolumn{3}{|c|}{ Nonhematologic adverse events ( $\geq 10 \%$ ) } \\
\hline Nausea & $18(81.8)$ & $0(0)$ \\
\hline Vomiting & $4(18.2)$ & $0(0)$ \\
\hline Constipation & $19(86.4)$ & $0(0)$ \\
\hline Diarrhea & $5(22.7)$ & $0(0)$ \\
\hline Stomatitis & $5(22.7)$ & $0(0)$ \\
\hline Anorexia & $20(90.9)$ & $1(4.5)$ \\
\hline Fatigue & $15(68.2)$ & $1(4.5)$ \\
\hline Pain & $6(27.3)$ & $0(0)$ \\
\hline Fever & $3(13.6)$ & $0(0)$ \\
\hline Weight loss & $3(13.6)$ & $0(0)$ \\
\hline Alopecia & $15(68.2)$ & $0(0)$ \\
\hline Rash & $6(27.3)$ & $0(0)$ \\
\hline AST increase & $4(18.2)$ & $0(0)$ \\
\hline ALT increase & $9(40.9)$ & $0(0)$ \\
\hline ALP increase & $11(50.0)$ & $0(0)$ \\
\hline Blood bilirubin increase & $4(18.2)$ & $0(0)$ \\
\hline Creatinine increase & $7(31.8)$ & $0(0)$ \\
\hline Hypoalbuminemia & $18(81.8)$ & $0(0)$ \\
\hline Hyperkalemia & $15(68.2)$ & $1(4.5)$ \\
\hline Hypocalcemia & $4(18.2)$ & $0(0)$ \\
\hline Hypokalemia & $5(22.7)$ & $0(0)$ \\
\hline Hyponatremia & $5(22.7)$ & $4(18.2)$ \\
\hline Peripheral sensory neuropathy & $6(27.3)$ & $1(4.5)$ \\
\hline Myalgia & $3(13.6)$ & $0(0)$ \\
\hline Lung infection & $4(18.2)$ & $4(18.2)$ \\
\hline
\end{tabular}

AST aspartate aminotransferase, $A L T$ alanine aminotransferase

results of our study may be promising in the future treatment of NSCLC.

Myelosuppression was mild, and the response rate was promising. As such, weekly nab-paclitaxel plus cisplatin with few treatment delays/skipped treatments (which rarely require schedule changes) could conceivably be a promising candidate for combination therapy with antiPD-1/PD-L1 antibodies.

\section{Conclusions}

Accordingly, weekly nab-paclitaxel plus cisplatin could be an easy-to-handle treatment option that is highly efficacious with a low incidence of hematological toxicity.
Since weekly nab-paclitaxel plus cisplatin is considered promising as a base regimen in combination with ICIs, we would like to conduct a clinical trial of anti-PD-1/ -PD-L1 antibodies combined with weekly nab-paclitaxel plus cisplatin for NSCLC in the future.

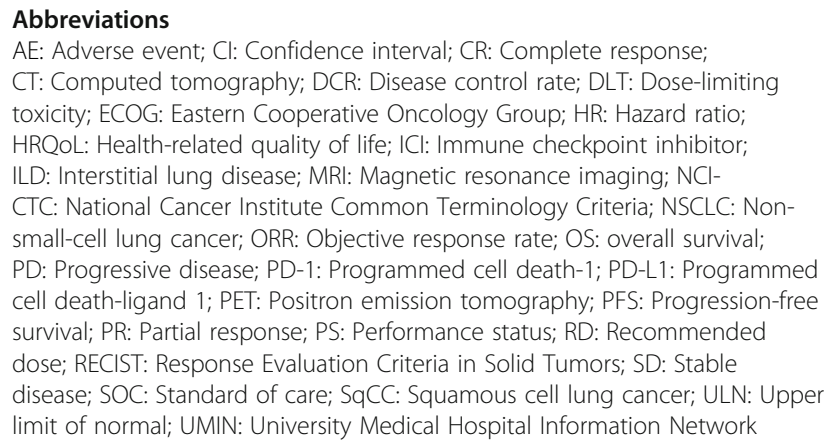

\section{Acknowledgements}

We thank all patients and investigators who participated in this study. This study was partially presented at the European Lung Cancer Conference 2018, Geneva, Switzerland (April 13, 2018) and the 2018 Japanese Society of Medical Oncology Annual Meeting, Kobe, Japan (July 19, 2018).

\section{Authors' contributions}

$\mathrm{YH}, \mathrm{RU}, \mathrm{SM}, \mathrm{SN}, \mathrm{Fl}$ and MS carried out the study design. YH, RU, SM and MS analyzed and interpreted the study data. YK1, SI, TI, YU, YK2, RT, TK and KN provided the study materials or patients. YH and MS prepared and edited the manuscript. All authors read and approved the final manuscript.

\section{Funding}

Financial support for this research was provided by Taiho Pharmaceutical, which had no role in the design of the study; collection, analysis, and interpretation of the data; or writing of the manuscript.

\section{Availability of data and materials}

The datasets used and/or analyzed during the current study are available from the corresponding author on reasonable request.

\section{Ethics approval and consent to participate}

This study was approved by the ethical review board of Hyogo Cancer Center (approval reference number R-111), the ethical review board of Saitama Cancer Center (approval reference number CA013-22), and the Ethics Committee, Osaka International Cancer Institute (approval reference number 1311253188). This study was conducted in accordance with the ethical principles in the Declaration of Helsinki. The study has been registered under the University Medical Hospital Information Network (UMIN) Clinical Trials Registry: identifier UMIN 000011776 . All patients provided written informed consent before enrollment. The informed consent form also contained an agreement for the publication of the study results.

\section{Consent for publication}

Not applicable.

\section{Competing interests}

YH has received grants and personal fees from Ono Pharmaceutical and MSD as well as personal fees from AstraZeneca, Boehringer Ingelheim, Chugai Pharmaceutical, Eli Lilly, Novartis and Taiho Pharmaceutical. TI has received personal fees from AstraZeneca, Chugai Pharmaceutical, Ely Lilly, MSD and Ono Pharmaceutical. TK has received grants and personal fees from AstraZeneca, Boehringer Ingelheim, Chugai Pharmaceutical, Eli Lilly, MSD, Novartis, Ono Pharmaceutical, Pfizer, and Taiho Pharmaceutical as well as grants from Merck Serono, Regeneron Pharmaceuticals, and Takeda Pharmaceutical as well as personal fees from Bristol-Myers Squibb and TEIJIN PHARMA. KN has received grants and personal fees from Boehringer Ingelheim as well as personal fees from AstraZeneca and Chugai Pharmaceutical. RU has received personal fees from Eisai and CAC Croit. SM 
has received grants and personal fees from Boehringer Ingelheim as well as personal fees from AstraZeneca, Bristol-Myers Squibb, Chugai Pharmaceutical, Eli Lilly, MSD, Ono Pharmaceutical, Pfizer and Taiho Pharmaceutical. Fl has received grants and personal fees from AstraZeneca, Boehringer Ingelheim, Bristol-Myers Squibb, Chugai Pharmaceutical, MSD, and Ono Pharmaceutical as well as personal fees from Eli Lilly, Kyowa Hakko Kirin, Novartis, Pfizer and Taiho Pharmaceutical. MS has received grants and personal fees from AstraZeneca, Boehringer Ingelheim, Bristol-Myers Squibb, Chugai Pharmaceutical, Eli Lilly, MSD, Novartis, Ono Pharmaceutical, and Pfizer as well as grants from AbbVie and Ignyta. All remaining authors have declared no conflicts of interest.

\section{Author details}

'Department of Thoracic Oncology, Hyogo Cancer Center, 13-70 Kitaoji-cho, Akashi-shi, Hyogo 673-8558, Japan. ²Department of Thoracic Oncology, Osaka International Cancer Institute, Osaka, Japan. ${ }^{3}$ Department of Biomedical Statistics and Bioinformatics, Kyoto University Graduate School of Medicine, Kyoto, Japan. ${ }^{4}$ Department of Medical Oncology, Takarazuka City Hospital, Takarazuka, Japan.

Received: 24 July 2019 Accepted: 29 January 2020

Published online: 11 February 2020

\section{References}

1. Boer HH, Moorer-van Delft CM, Muller LJ, Kiburg B, Vermorken JB, Heimans J. Ultrastructural neuropathologic effects of Taxol on neurons of the freshwater snail Lymnaea stagnalis. J Neuro-Oncol. 1995;25(1):49-57.

2. Windebank AJ. The vehicle for cyclosporine is neurotoxic in vitro. Ann Neurol. 1997;41(4):563-4

3. Authier N, Gillet JP, Fialip J, Eschalier A, Coudore F. Description of a short-term Taxol-induced nociceptive neuropathy in rats. Brain Res. 2000;887(2):239-49.

4. Desai N, Trieu V, Yao Z, Louie L, Ci S, Yang A, Tao C, De T, Beals B, Dykes D, et al. Increased antitumor activity, intratumor paclitaxel concentrations, and endothelial cell transport of cremophor-free, albumin-bound paclitaxel, ABI007, compared with cremophor-based paclitaxel. Clin Cancer Res. 2006; 12(4):1317-24

5. Bonomi P, Kim K, Fairclough D, Cella D, Kugler J, Rowinsky E, Jiroutek M, Johnson D. Comparison of survival and quality of life in advanced nonsmall-cell lung cancer patients treated with two dose levels of paclitaxel combined with cisplatin versus etoposide with cisplatin: results of an eastern cooperative oncology group trial. J Clin Oncol. 2000;18(3):623-31.

6. Rosell R, Gatzemeier U, Betticher DC, Keppler U, Macha HN, Pirker R, Berthet $P$, Breau $J L$, Lianes $P$, Nicholson $M$, et al. Phase III randomised trial comparing paclitaxel/carboplatin with paclitaxel/cisplatin in patients with advanced non-small-cell lung cancer: a cooperative multinational trial. Ann Oncol. 2002;13(10):1539-49.

7. Sakai H, Yoneda S, Tamura T, Nishiwaki Y, Yokoyama A, Watanabe K, Saijo N. A phase II study of paclitaxel plus cisplatin for advanced nonsmall-cell lung cancer in Japanese patients. Cancer Chemother Pharmacol. 2001;48(6):499-503.

8. Hotta K, Matsuo K, Ueoka H, Kiura K, Tabata M, Tanimoto M. Meta-analysis of randomized clinical trials comparing Cisplatin to carboplatin in patients with advanced non-small-cell lung cancer. J Clin Oncol. 2004;22(19):3852-9.

9. Ardizzoni A, Boni L, Tiseo M, Fossella FV, Schiller JH, Paesmans M, Radosavljevic D, Paccagnella A, Zatloukal P, Mazzanti P, et al. Cisplatinversus carboplatin-based chemotherapy in first-line treatment of advanced non-small-cell lung cancer: an individual patient data meta-analysis. J Natl Cancer Inst. 2007:99(11):847-57.

10. Jiang J, Liang X, Zhou X, Huang R, Chu Z. A meta-analysis of randomized controlled trials comparing carboplatin-based to cisplatin-based chemotherapy in advanced non-small cell lung cancer. Lung Cancer. 2007; 57(3):348-58,

11. Socinski MA, Bondarenko I, Karaseva NA, Makhson AM, Vynnychenko I, Okamoto I, Hon JK, Hirsh V, Bhar P, Zhang H, et al. Weekly nabpaclitaxel in combination with carboplatin versus solvent-based paclitaxel plus carboplatin as first-line therapy in patients with advanced non-small-cell lung cancer: final results of a phase III trial. J Clin Oncol. 2012;30(17):2055-62.

12. Wilson EB. Probable inference, the law of succession, and statistical inference. J Am Stat Assoc. 1927;22(158):209-12.
13. Brookmeyer RC, J. A confidence interval for the median survival time. Biometrics. 1982;38(1):29-41.

14. Paz-Ares LG, de Marinis F, Dediu M, Thomas M, Pujol JL, Bidoli P, Molinier O, Sahoo TP, Laack E, Reck M, et al. PARAMOUNT: final overall survival results of the phase III study of maintenance pemetrexed versus placebo immediately after induction treatment with pemetrexed plus cisplatin for advanced nonsquamous non-small-cell lung cancer. J Clin Oncol. 2013; 31(23):2895-902.

15. Paz-Ares L, Luft A, Vicente D, Tafreshi A, Gumus M, Mazieres J, Hermes B, Cay Senler F, Csoszi T, Fulop A, et al. Pembrolizumab plus chemotherapy for squamous non-small-cell lung Cancer. N Engl J Med. 2018;379(21):2040-51.

16. Mazieres J, Kowalski D, Luft A, Vicente D, Tafreshi A, Gumus M, Laktionov K, Hermes B, Cicin I, Rodriguez-Cid J, et al. Health-Related Quality of Life With Carboplatin-Paclitaxel or nab-Paclitaxel With or Without Pembrolizumab in Patients With Metastatic Squamous Non-Small-Cell Lung Cancer. J Clin Oncol. 2020;38(3):271-80

17. West H, McCleod M, Hussein M, Morabito A, Rittmeyer A, Conter HJ, Kopp $\mathrm{H}-\mathrm{G}$, Daniel D, McCune S, Mekhail T, et al. Atezolizumab in combination with carboplatin plus nab-paclitaxel chemotherapy compared with chemotherapy alone as first-line treatment for metastatic non-squamous non-small-cell lung cancer (IMpower130): a multicentre, randomised, openlabel, phase 3 trial. Lancet Oncol. 2019;20(7):924-37.

18. Kenmotsu H, Yoh K, Mori K, Ono A, Baba T, Fujiwara Y, Yamaguchi O, Ko R, Okamoto H, Yamamoto N, et al. Phase II study of nab-paclitaxel + carboplatin for patients with non-small-cell lung cancer and interstitial lung disease. Cancer Sci. 2019;110(12):3738-45.

\section{Publisher's Note}

Springer Nature remains neutral with regard to jurisdictional claims in published maps and institutional affiliations.

Ready to submit your research? Choose BMC and benefit from:

- fast, convenient online submission

- thorough peer review by experienced researchers in your field

- rapid publication on acceptance

- support for research data, including large and complex data types

- gold Open Access which fosters wider collaboration and increased citations

- maximum visibility for your research: over $100 \mathrm{M}$ website views per year

At $\mathrm{BMC}$, research is always in progress.

Learn more biomedcentral.com/submissions 